\title{
The influence of hole finishing strategies on quality
}

\author{
Vlad Bocanet ${ }^{1}$ and Nicolae Panc ${ }^{1, *}$ \\ ${ }^{1}$ Technical University of Cluj-Napoca, Department of Manufacturing Engineering, no.103-105, Bvd. \\ Muncii, Cluj-Napoca, Romania
}

\begin{abstract}
There are many strategies that the operator can use for hole finishing, depending on the equipment available to him. The issue at hand is choosing the optimal strategy when equipment is available for more than one possible manufacturing method. The present work analyses four types of finishing strategies for holes and determines the advantages and disadvantages of each, from a quality perspective.
\end{abstract}

\section{Introduction}

In our days, there are many technologies for manufacturing a part. Each technology has its advantages and disadvantages. Depending on the requirements that the part must satisfy, the most appropriate technology is chosen. If theoretically this is easily done, in practice it is limited by existing possibilities. The usage of optimal technologies is not always possible and, thus, it is necessary to use the optimal existing technologies [1].

In the case of hole finishing there are multiple ways of obtaining the same hole through different strategies or by using different tools. The same diameter hole can be obtained by using a mill, reamer, boring bar, turning tool or abrasive body [2]. Choosing the optimal strategy depends on the existing equipment, the machine tools used, the shape of the part being machined and many other factors that influence the machining strategy. A precise hole is an interior revolution surface that is different from a hole through its superior accuracy, low shape errors (which are standardized) and high surface quality [2-4].

The aim of this article is to study the way in which the quality of a precision hole is influenced by the chosen manufacturing strategy. The quality of a precision hole considers four aspects deemed relevant: dimensional, shape and actual position accuracy, as well as the resulting surface. All these aspects are important in precision holes with a functional role (sliding or ball bearings, guide bushings, centering elements etc.). Thus, the surface is important for precision holes that have shafts performing rotational or reciprocating movement because of the need of adequate lubrication. In such situations, the surface can have an influence on the maintenance of the oil film [5]. The actual position accuracy is important in the case when the precision hole is used for guiding an element passing through it. The form accuracy is also important when the precision hole needs to ensure a certain load capacity for its corresponding element. The lack of an appropriate form

\footnotetext{
*Corresponding author: nicolae.panc@tcm.utcluj.ro
} 
accuracy can lead to an uneven distribution of the load on the hole surface leading to uneven wear and, as a result, a low reliability $[6,7]$.

Next, we will compare the quality of the precision holes obtained though the most common manufacturing techniques and identify the optimal technology but also determine the influence of certain factors on hole quality.

\section{Research methodology}

To reach the proposed aim, a certain methodology was used, which is presented briefly in figure 1. In total four different techniques were used on three different material. After the rough boring, the four methods were applied for the finishing part. The characteristics were measured and the data was analyzed. The obtained results were analyzed quantitatively.

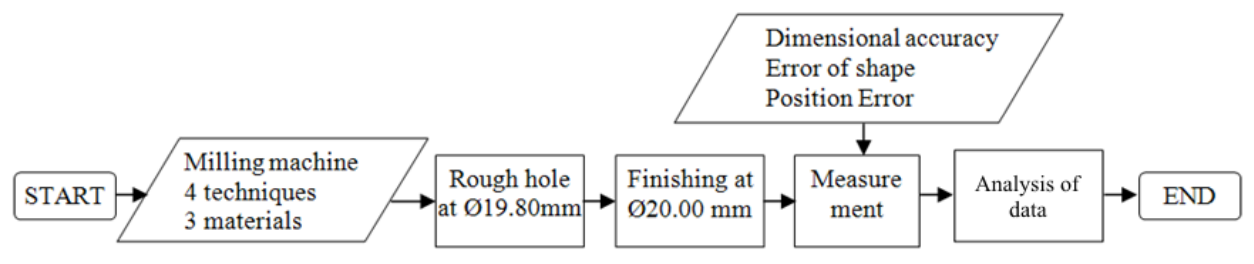

Fig. 1. Flowchart of the proposed methodology.

\subsection{Experimental design}

The experiment consisted of machining three different types of materials from the most commonly used material groups in industry: steel and aluminum alloys and plastics. For each group, a material was chosen that is frequently used:

- Steel alloy - S395;

- Aluminum alloy - AW7075;

- Plastics - copolymer POM-C.

The two parts that were machined from each material are presented in Figure 2 and 3. Figure 2 shows the part drawing while Figure 3 shows the actual parts that were machined.

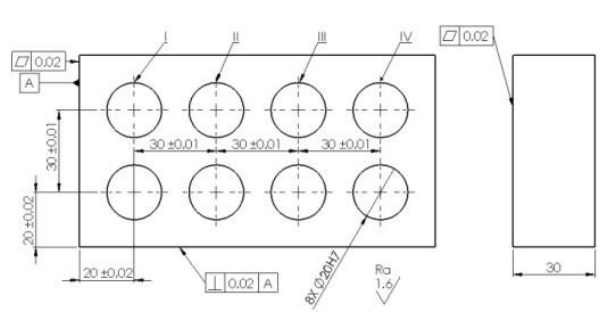

Fig. 2. Drawing test part.

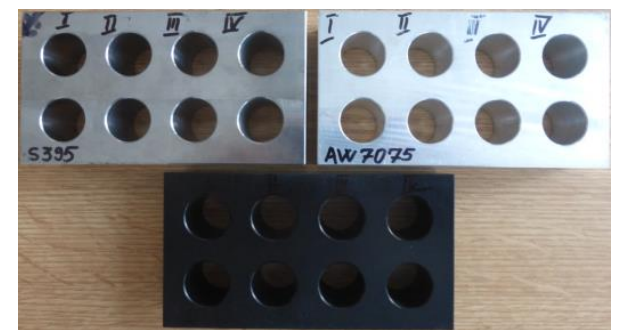

Fig. 3. Manufactured parts.

Two holes were executed in each part, for each of the four strategies, a total of 24 precision holes resulting. The four strategies used are:

I - helical milling;

II - profile milling;

III - head boring;

IV - reaming. 
The holes were first drilled to $\varnothing 19.80 \mathrm{~mm}$ and then, the Ø20H7 diameter was obtained through a single pass of the tool.

\subsection{Equipment and measurements}

The following equipment was used for machining and measuring the precision holes:

- Vertical machining center (VMC);

- TRM50/50 Boring head Testarossa D'Andrea;

- HSS Reamer for Ø20H7;

- Drill Ø19.80 mm;

- Solid carbide end mill, $\varnothing 16, \mathrm{z}=4 \mathrm{~mm}$;

The machining parameters that were used are presented in Table 1. The same work conditions were used for all material types in order to do a comparative quantitative study.

Table 1. Parameters of cutting bores.

\begin{tabular}{|l|c|c|c|}
\hline \multirow{2}{*}{ Method } & Feed & Spin & Tooling allowance \\
\cline { 2 - 4 } & {$[\mathrm{mm} / \mathrm{min}]$} & {$[\mathrm{rev} / \mathrm{min}]$} & {$[\mathrm{mm}]$} \\
\hline Helical milling & 1000 & 3500 & 0.02 \\
\hline Contour milling & 400 & 3500 & 0.02 \\
\hline Head boring & 120 & 2800 & 0.02 \\
\hline Reaming & 160 & 80 & 0.02 \\
\hline
\end{tabular}

The measurement was done on a Zeiss Prismo Navigator Coordinate Measuring Machine (CMM) equipped with a VAST sensor and $5 \mathrm{~mm}$ ruby tactile probe. According to the manufacturer the CMM has a length measurement error of $0.5+\mathrm{L} / 500 \mu \mathrm{m}$.

\section{Results}

The quality of the precision holes was determined through the measuring of the dimensional and surface quality characteristics. In the case of the dimensional measurements the dimensional accuracy, error of shape and position error were determined.

After the measurement on the CMM, the data was stored in an Excel worksheet. When processing the data, two main variables were taken into account: the working method used and the material of the part. The averages were calculated for the diameter, the circularity and the cylindricity.

\subsection{Dimensional accuracy}

If we compare the methods numerically, we get the data in Table 2. From the table, it can be seen that although head boring and reaming give on average the least deviation from the nominal value, their spread is much greater than that of helical and profile milling.

Table 2. The average diameter and the standard deviation for the values of each working method, in millimeters.

\begin{tabular}{|l|c|c|c|c|}
\hline & Helical milling & Profile milling & Head Boring & Reaming \\
\hline Average & 20.007 & 19.993 & 19.995 & 19.995 \\
\hline Std. Dev. & 0.008 & 0.010 & 0.018 & 0.054 \\
\hline
\end{tabular}

Graphically we can compare either the nominal diameter obtained (Figure 4.a) or the deviation from the nominal value (Figure 4.b). If we also add the "material" dimension into 
the analysis, it can be seen from Figure 4 that reaming and head boring have the greatest variation while the first two methods have comparable spreads across the material variable.

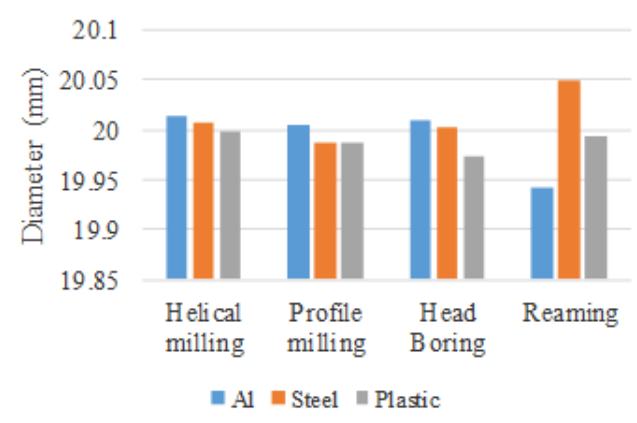

a)

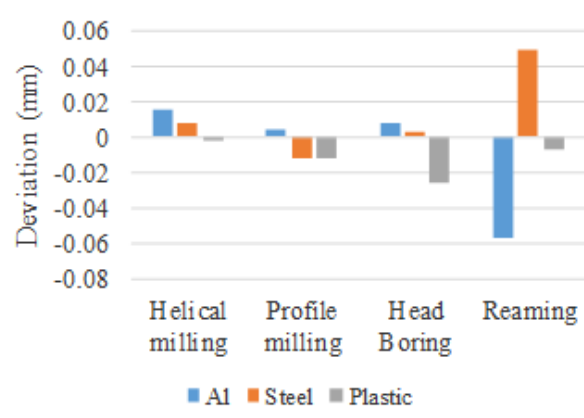

b)

Fig. 4. Influence of the working method on the diameter, a) absolute values, b) relative to the nominal value.

If we consider the influence of the material (Figure 5) we notice that plastic has the least variation across working methods in comparison with metals. We also see that, in the case of metals, reaming skews the distribution of values quite a lot.

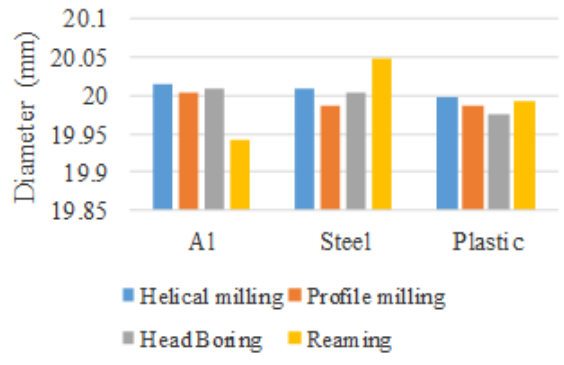

a)

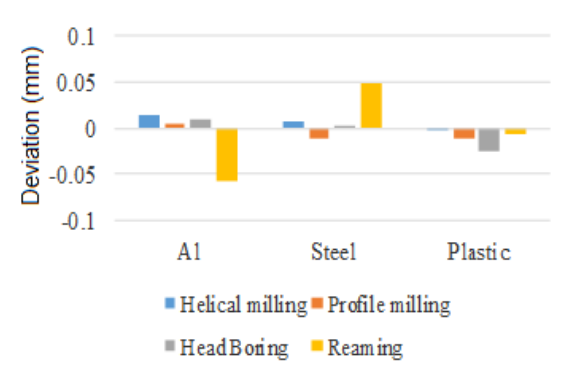

b)

Fig. 5. Influence of the material on the diameter, a) absolute values, b) relative to the nominal value.

\subsection{Shape deviation}

Shape deviations were measured by using circularity at three different levels and the cylindricity. The three considered levels were: upper section ( $3 \mathrm{~mm}$ from the top), middle section (15 $\mathrm{mm}$ from the top) and lower section (27 $\mathrm{mm}$ from the top). The profile of the precision hole can be determined by observing the variation in diameter from one section to the other (Figure 6). It can be seen that deviations from the nominal value tend to be higher in the upper section and lower in the lower section. For aluminum and plastic, the initial diameter tends to be smaller and then approaches the nominal value while for steel the upper diameter is larger (Figure 6.a).

If we compare the average circularity (computed by averaging the circularity of the three sections) for the precision holes, taking into account working method and material, we get the graphs in Figure 7. It can be seen that the highest deviation is for plastic and for reaming.

We get similar results for cylindricity, as shown in Figure 8 although the other values seem to be close together. 


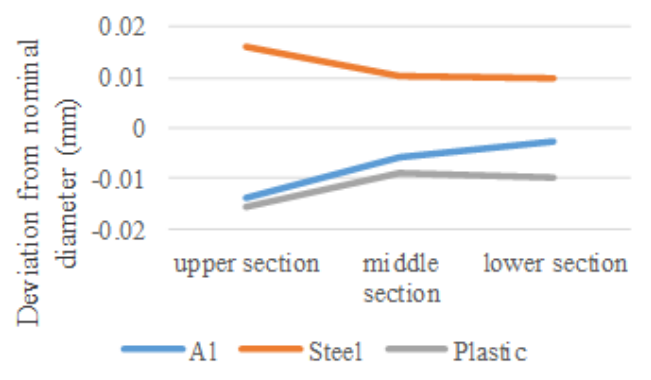

a)

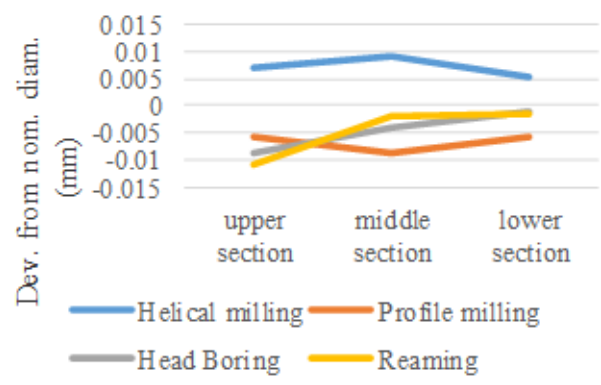

b)

Fig. 6. Influence of the precision hole shape, a) material, b) working method.

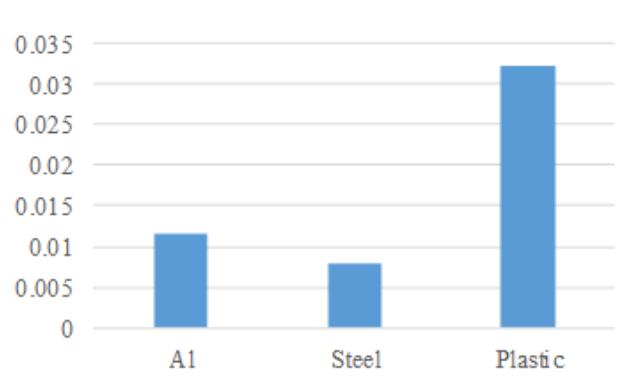

a)

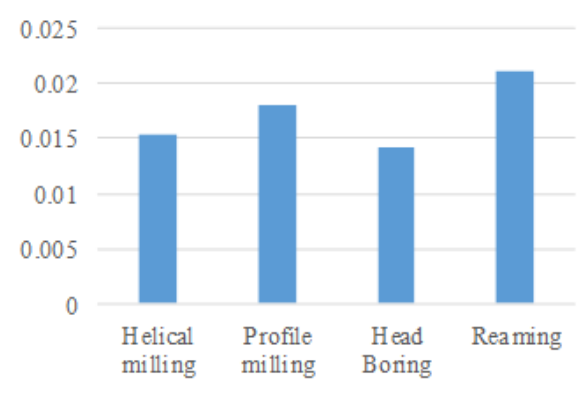

b)

Fig. 7. Influence on the average circularity of the precision hole, a) of the material, b) of the working method.

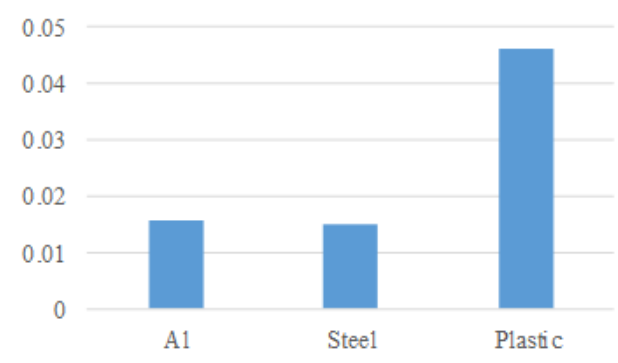

a)

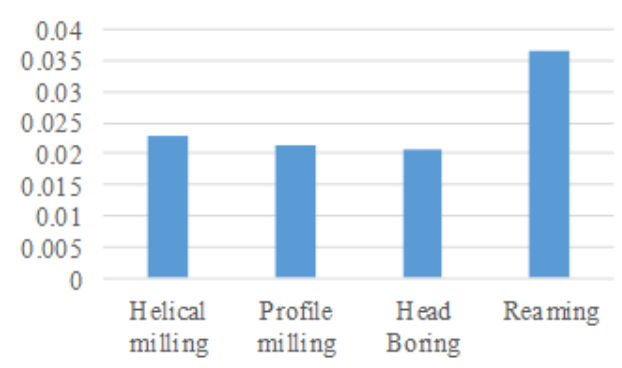

b)

Fig. 8. Influence on the average cylindricity of the precision hole, a) of the material, b) of the working method.

\section{Conclusions}

The present paper analyzed the influence of machining strategy on hole quality. During the research both machining strategy and material were taken into consideration.

After interpreting the results of this study, the following conclusions were reached:

- The highest quality can be obtained by helical milling, it being the most stable strategy, with a high repeatability rate resulting from the low standard deviation $(<0.01 \mathrm{~mm})$;

- Reaming is the most unstable strategy, being highly influenceable by tool wear; 
- Plastics (POM) seem to be fairly indifferent to machining strategy with a constant dimensional accuracy;

- Helical milling is recommended for obtaining a high form precision for holes;

- Head boring followed by helical milling is recommended for obtaining a high circularity;

- To obtain a good cylindricity, one could use either head boring, helical milling or profile milling.

The conclusions drawn in this paper are based on the results of this study. However, they need to be confirmed through a more extensive study, containing a higher number of parts in order to get more statistically relevant results.

The results presented in this paper were obtained with the support of the Technical University of ClujNapoca through the research Contract no. 2002/12.07.2017, Internal Competition CICDI-2017.

\section{References}

1. I.Vuscan, N.Panc, Bazele prelucrarilor mecanice, (Ed. Scoala Ardeleana, Cluj-Napoca (2015)

2. N. Panc, V. Bocanet, M. Bulgaru, C. Beldean, Acta Technica Napocensis, Series Applied Mathematics and Mechanics, 57 (1) (2014)

3. I.A. Popan, A. Popan, S.C. Cosma, A. Carean, International Conference on Computing and Solutions in Manufacturing Engineering - CoSME'16, published in MATEC Web of Conferences 94 (2017)

4. I.A. Popan, N. Balc, A. Carean, I.A. Popan, Proceeding of 16th International Scientific Conference - Automation in Production, Planning and Manufacturing, ZilinaOscadnica, Slovakia, 117-122 (2015)

5. J. Paulo Davim Editor, Surface Integrity in Machining, (Springer-Verlag London Limited) (2010)

6. S.A. Radu, A. C. Popescu, N. Balc, N. Panc, Proceedings in ARSA-Advanced Research in Scientific Areas (2014)

7. I.A. Popan, N. Balc, A. Popan, D. Fratila, A. Trif, Applied Mechanics and Materials, 808, pp 54-59 (2015) 